\title{
PRESOS DE GRAPO EN UNA PRISIÓN DE MÁXIMA SEGURIDAD: LUCHA Y RESISTENCIA EN HERRERA DE LA MANCHA (1979-1983) ${ }^{1}$
}

\section{PRISONERS OF GRAPO IN A MAXIMUM SECURITY JAIL: STRUGGLE AND RESISTANCE IN HERRERA DE LA MANCHA (1979-1983)}

\author{
Eduardo Parra Iñesta \\ Universidad de Castilla-La Mancha
}

Entregado el 24-7-2015 y aceptado el 5-4-2016

Resumen: Los Grupos de Resistencia Antifascista Primero de Octubre, GRAPO, fueron uno de los trágicos protagonistas de la Transición. Nacidos como un partido a la izquierda del Partido Comunista de España, el PCE (r), terminaron desarrollando un brazo armado a partir de 1975. Con las consecuentes detenciones fruto de su actividad, la historia de GRAPO se empezó a escribir desde la cárcel, sobre todo a partir de 1978. En este artículo nos centramos en la experiencia de los presos de esta organización en la cárcel de Herrera de la Mancha, primera cárcel de máxima seguridad construida en el Estado. Fueron llevados allí en 1979 por un castigo, la fuga de cinco compañeros de la prisión de Zamora, y en el penal manchego vivieron una experiencia marcada por la lu-

\footnotetext{
${ }^{1}$ Este articulo forma parte del proyecto de investigación HAR2013-40621-P (financiado por el Ministerio de Economía y Competitividad), que lleva por título «El control del delito en la España contemporánea: discursos de seguridad, instituciones punitivas y prácticas de excepcionalidad» del cual es investigador principal el profesor Pedro Oliver Olmo (Universidad de Castilla-La Mancha).
} 
cha y la resistencia contra el sistema penitenciario, como en la huelga de hambre de 1981 en la que uno de sus miembros murió.

Palabras clave: Transición Española, GRAPO, Herrera de la Mancha, huelgas de hambre.

Abstract: The Grupos de Resistencia Antifascista Primero de Octubre, $G R A P O$, were one of the tragic characters of the Spanish Transition. They were born as a left wing of the Spanish Comunist Party, with the name PCE (r), they finally developed a military branch from 1975. After the detentions of their members, because of their activities, the history of GRAPO started to being written from the jail, specially after 1978. In this article we have focused in the experience of the prisioners of GRAPO in the jail of Herrera de la Mancha, the first maximum secutiry jail built in Spain. They were taken there in 1979 because of a penalty, the escape of five comrades in the prison of Zamora, and they lived in the manchegan penitentiary an experienced marked by the fight and the resistance against the penitenciary sistem, as the hunger strike of 1981 in which one of their members died.

Key words: Spanish Transition, GRAPO, Herrera de la Mancha, hunger strikes 
«La Mancha desespera siempre desde un canguro, aunque el sol es de invierno y se agradece; un horizonte tan amplio, tan limpio y tan humano aturdirá siempre al que lo contempla entre barrotes. Don Quijote enloqueció cuando lo enjaularon» ${ }^{2}$

En este artículo pretendemos analizar la experiencia de los presos del PCE (r) y de GRAPO en la prisión de Herrera de la Mancha, donde permanecieron internados desde diciembre de 1979 hasta noviembre de 1983. Un relato que ellos mismos construyeron en clave de lucha y resistencia frente al régimen de este centro penitenciario de máxima seguridad y el sistema carcelario en general, algo que ellos planteaban como algo complementario a sus acciones en la calle, en la que practicaban la lucha armada y el terrorismo. Su llegada estuvo relacionada con la fuga de la cárcel de Zamora, mientras que su presencia en el penal manchego acabó con la llegada de los reclusos de ETA a finales de 1983.

Esta reflexión ha sido posible con el aporte documental de fuentes primarias y secundarias, las cuales podemos agrupar en cuatro tipos distintos: monografías y memorias, documentación judicial, fuentes orales y publicaciones periódicas.

En primer lugar, hemos consultado la bibliografía sobre GRAPO y el PCE (r), escasa en comparación con otras organizaciones armadas como ETA. Algunos militantes como Juan García Martín ${ }^{3}$ han cumplido la labor de fijar el discurso de la organización. Este, reconstruye el decurso de este grupo con un tono apologético bastante evidente. También contamos con libros de periodistas como el de Rafael Gómez Parra, ${ }^{4}$ en el que se vislumbran ciertas simpatías, pero con un tono más crítico y riguroso. Otra obra de interés es la aportación que con enfoque criminológico realiza Horacio Roldán Barbero. ${ }^{5}$ En cuanto a las memorias colectivas o personales de presos de GRAPO, como Crónicas de Herrera de la Mancha ${ }^{6}$,

2 Colectivo de presos de PCE (r) y GRAPO: Crónicas de Herrera de la Mancha. Ediciones Contracanto, Madrid, 1983, p. 14.

3 J. García Martín, Historia del PCE(r) y de los GRAPO. Ediciones Contracanto, Madrid, 1984. 1991.

${ }^{4}$ R. Gómez Parra, GRAPO. Los hijos de Mao. Ediciones Fundamentos, Madrid,

${ }^{5}$ H. Roldán Barbero, Los Grapo: Un estudio criminológico. Editorial Comares, Granada, 2008.

${ }^{6}$ Colectivo de presos de PCE (r) y GRAPO, op. cit. 
Morir para sobrevivir ${ }^{7}$, Memoria Antifascista ${ }^{8}$ y El tazón de hierro ${ }^{9}$, se centran, especialmente los dos primeros, en la experiencia del encarcelamiento en la prisión de Herrera de la Mancha.

En segundo lugar, hemos accedido a documentación del Sumario $22 / 79$, en el que varios funcionarios de Herrera de la Mancha fueron procesados por malos tratos a presos en el verano de 1979. Aunque este caso atañe a presos sociales, contamos con documentación de la época de los presos del GRAPO en el libro de Manolo Revuelta, que sacó a la luz pública esta información. ${ }^{10}$

Por otra parte, hemos tenido acceso a testimonios orales a través de las entrevistas realizadas a José Balmón, encarcelado en Herrera de la Mancha entre 1981 y 1982 y responsable de organización del PCE (r), y a Carlos García Valdés, Director General de Instituciones Penitenciarias entre 1978 y 1979, quien sufrió en sus propias carnes un atentado fallido de GRAPO.

Por último, hemos revisado fuentes hemerográficas de la época. En concreto, se han consultado cinco publicaciones diarias como son Egin, Lanza, El País, Diario 16 y ABC, que cubren un amplio espectro ideológico del periodo que tratamos.

\section{El origen del GRAPO}

\subsection{La OMLE y su conversión en el PCE (r) (1968-1975)}

Para entender el origen de GRAPO debemos atender al desarrollo del Partido Comunista de España reconstituido, PCE (r), núcleo a partir del cual nacería. El contexto del nacimiento de este partido se sitúa en los años sesenta, cuando ya se había producido el desencuentro entre la URSS y China a consecuencia del revisionismo soviético. En España tam-

${ }^{7}$ AFAPP, Morir para sobrevivir. La muerte de Juan José Crespo Galende y la lucha de los presos políticos contra los planes de aniquilamiento en las cárceles fascistas. AFAPP, Madrid, 1982.

${ }^{8}$ F. Brotons Beneyto. Memoria antifascista: Recuerdos en medio del camino. Miatzen Sarl, 2002.

${ }^{9}$ F. Novales, El tazón de Hierro. Crítica, Barcelona, 1989.

10 M. Revuelta, Sumario 22/79. Herrera de la Mancha: Un caso ejemplar. Ed. de la Piqueta, Madrid, 1980. 
bién se produjeron combates ideológicos en el campo del comunismo, que motivaron escisiones a la izquierda del PCE, como la ORT. En el caso del PCE (r), su predecesor fue la OMLE, Organización Marxista-Leninista de España, nacida en 1968 en Paris por inmigrantes españoles, orientada hacia la ortodoxia marxista-leninista y el maoísmo. Esta organización consideró la lucha armada como una posibilidad real y factible. Sin embargo, estaban poco implantados en España, en 1970 solo tenían pequeños grupos autónomos en Madrid, Cádiz y Vigo. ${ }^{11}$

En 1969 entró en la OMLE Manuel Pérez Martínez, Arenas, quien sería el principal responsable de la conversión de la organización en un partido. Contribuyó en la formulación teórica del grupo, abandonando la idea de que España era una colonia yanqui, algo muy en boga en los grupos «prochinos» de la época. Así pues, consideraba a España como un país con capitalismo avanzado en el que era necesaria una revolución socialista. $^{12}$

Tras la quinta reunión general de la OMLE en 1971, el poder pasó al interior, adoptando a su vez una estructura leninista, de centralismo democrático. Entre 1971 y 1973 se consolidaron al tiempo que se reforzaba el liderazgo de Arenas. Su objetivo era reconstruir el Partido Comunista original, que había sido disgregado por los revisionistas, para devolverlo a la ortodoxia marxista-leninista. ${ }^{13}$ En esos años estuvieron presentes en la lucha obrera, sobre todo en los sectores del metal y textil de Madrid. Planteaban su lucha autónomamente, sin atender a las convocatorias de CCOO, a los que tachaban de revisionistas, al igual que al PCE. ${ }^{14}$

En junio de 1973 tuvo lugar la primera Conferencia de la OMLE. En ella propusieron su programa de diez puntos entre los que se incluían ideas como la necesidad de un gobierno provisional democrático revolucionario, el deber de armar al pueblo, la liberación de presos políticos, el derecho de autodeterminación o la nacionalización de grandes propiedades. Estos objetivos se conseguirían, según ellos, gracias a una sólida alianza de la clase obrera y el campesinado. ${ }^{15}$

Tras esta Conferencia empezaron a expandirse poco a poco por el territorio nacional. En junio de 1975 dieron el paso definitivo para cons-

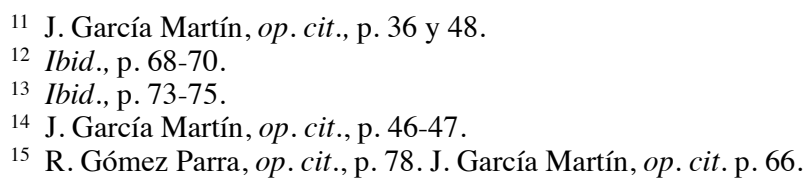


tituir el PCE (r), en el Congreso Fundacional de Torrelavega. ${ }^{16}$ En el Comité Central fueron elegidos Enrique Cerdán, Abelardo Collazo, Juan Carlos Delgado, Pio Moa y Manuel Pérez, Arenas, este último también Secretario General, quienes provenían preferentemente del mundo obrero y estudiantil. ${ }^{17}$ En este Congreso se incidió en el carácter marxista-leninista de la organización y la necesidad de reconstruir el Partido. Consideraban imprescindible una buena organización, así como el desenmascaramiento de falsos partidos obreros. El PCE (r), como otros partidos de la izquierda revolucionaria de este periodo, aspiraba a ser el partido comunista único y se creía el principal representante de la ortodoxia marxista-leninista, algo que hizo que su relación con el resto de partidos de similar ideología fuese, cuanto menos, complicada. ${ }^{18} \mathrm{De}$ igual manera, en su análisis del contexto político declaraban que los problemas ya no se podían resolver por las urnas, sino que había que usar la fuerza revolucionaria. ${ }^{19}$

Por todo ello, el partido no entró en el juego electoral y no se presentó a las elecciones de 1977, al contrario que otros partidos en la órbita del comunismo revolucionario como PTE, ORT, MC y LCR quienes participaron en distintos frentes electorales, aunque sin obtener representación parlamentaria.

\subsection{Comienza la lucha armada, 1975-1976.}

En tiempos de la OMLE ya se había considerado la lucha armada como táctica. Entendían la violencia como la única medida posible para luchar contra el estado fascista, aunque eso sí, supeditada a las directrices del partido. Sin embargo, fueron una serie de circunstancias externas las que les llevaría a practicarla, como los fusilamientos del 27 de septiembre de 1975, últimos crímenes del estado franquista, en el que fueron ajusticiados tres presos del FRAP y dos de ETA político militar. Cuatro días más tarde, el 1 de octubre, asesinaban a cuatro agentes de la policía armada en respuesta, ante el estupor del Gobierno, que

16 F. Brotons Beneyto, op. cit., pp. 138-139.

${ }^{17}$ R. Gómez Parra, op. cit., p. 87.

18 G. Fernández Soldevilla y R. López Romo, Sangre, votos, manifestaciones: ETA y el nacionalismo vasco radical. Tecnos, Madrid, 2012, p. 300.

19 J. García Martín, op. cit., p. 100. 
ese mismo día había convocado una manifestación multitudinaria en la Plaza de Oriente de Madrid.

Aunque no fue su primer atentado, pues ya habían actuado en verano, ese día nacieron los Grupos de Resistencia Antifascista Primero de Octubre, que tomarían su nombre de aquella acción. Este hecho fue, por tanto, el primer «evento catalítico» en la historia de GRAPO, siguiendo la terminología que usa Horacio Roldán, en su camino hacia la lucha armada. $\mathrm{El}$ autor equipara este hecho a otros como la muerte del estudiante Benno Ohnesorg en el caso de la Baader-Meinhof. La ideología férrea y el periodo convulso de la Transición hicieron que la violencia siguiese siendo utilizada, ${ }^{20}$ en especial en el año de 1979, donde acometieron 31 de las 85 muertes que se les atribuyen. ${ }^{21}$ En estas acciones armadas, sus objetivos prioritarios fueron miembros del gobierno y militares. ${ }^{22}$

En otro orden de cosas, hubo muchos recelos acerca del nacimiento de este grupo, en el que se pensaba que militaban elementos infiltrados de la policía y de sectores ultraderechistas o al que directamente se le acusaba de haber sido gestado por los servicios secretos..$^{23}$ Las infiltraciones se dieron, pero al igual que en todas las organizaciones de este tipo. Pese a que la presencia de miembros como Pío Moa, ${ }^{24}$ que por su evolución posterior puedan hacernos pensar lo contrario, GRAPO era una organización de extrema izquierda, vinculado directamente al PCE(r). Ambos tenían una estructura abierta, ya que no era necesario militar en el partido para entrar en el grupo armado. ${ }^{25}$

También sobrevolaron sobre ellos acusaciones de fanatismo ${ }^{26}$, a consecuencia de sus atentados y de las huelgas de hambre a muerte que realizaron, tanto en 1981 como en 1989. La férrea disciplina que mantenían

${ }^{20}$ H. Roldán Barbero, op. cit., p. 75-78.

$21 \mathrm{http}$ //www.fundacionvt.org/index.php?option=com_dbquery\&Itemid=82\&task=Ex ecuteQuery\&qid=2\&previousTask Última visita 19-07-2015.

$22 \mathrm{~S}$. Baby, Le mythe de la transition pacifique. Violence et politique en Espagne (1975-1982). Casa Velázquez, Madrid, 2012, pp. 199-239.

23 «La fuga de Zamora» en El País, 19 diciembre 1979.

${ }^{24}$ Pío Moa se convirtió con el paso de los años en uno de los principales representantes del «revisionismo histórico» respecto a la Guerra Civil y el Franquismo, con una mirada hacia el régimen más amable. Por ejemplo, considera que la Guerra Civil comenzó en 1934 con la revolución de Asturias. «Un intelectualillo mediocre» en palabras de José Balmón.

${ }^{25}$ H. Roldán Barbero, op cit., p. 1-2.

26 «Entrevista con Antoni Asunción» en El País, 31 enero 1990. 
ayudó a que el Gobierno lo presentara como un grupo de fanáticos excesivamente ideologizados. Carlos García Valdés hace referencia a ello cuando habla del atentado fallido del que fue objeto por parte de GRAPO.

«Cuando el atentado, fue en semana santa, al lunes siguiente fui al Congreso a seguir negociando la ley penitenciaria. El atentado fue en abril de 1979, no me acuerdo si el 7, un miércoles santo. Aniversario de Haddad, una cosa siniestra. Fíjese usted las palabras de Bandrés con ETA en Soria. «Carlos me alegro mucho que estés bien. No ha sido ETA. Si es ETA, te mata» No era nunca, ni siquiera con ETA fue un tema personal. Bien porque aún se les hace el traslado, tal vez por la cercanía de Soria, tal vez por el trato, tal vez porque se les permite sus galerías independientes cuando estaban en Basauri... El GRAPO era otra cosa, era una locura... disparatado todo.» ${ }^{27}$

Pese a que esta idea haya perdurado en el tiempo, sería erróneo caracterizar a los militantes de GRAPO como fanáticos. Era un grupo muy ideologizado, sin duda, pero que actuaba según la lógica de su pensamiento político, en el cual la violencia era un arma tan válida como otra cualquiera, incluso hablando de terrorismo. Su uso de la vía armada se hace de una forma consciente e intencionada, lo cual incluso acrecienta la aversión hacia la agresión, pues se debe a la táctica y la reflexión y no a un impulso primario.

Otro hecho que les motivó a continuar practicando la lucha armada fueron las muertes de los obreros en la huelga del 3 de marzo de 1976 en Vitoria, tras las cuales lanzaron la campaña de bombas del 18 de julio de 1976. Pensaron que la débil reacción del Gobierno significaba que este no estaba preparado para contrarrestarles, por lo realizaron acciones de más envergadura ${ }^{28}$ Así, a finales de año pusieron en marcha la «Operación Cromo», consistente en los secuestros de Antonio María Oriol, Presidente del Consejo del Estado, el 11 de diciembre de 1976 y el del Teniente Emilio Villaescusa, Presidente del Consejo Supremo de Justicia Militar el 24 de enero de 1977, mismo día de la matanza de los abogados de Atocha, en plena «semana negra de la Transición». Ambos rehenes serían liberados por la Policía el 11 de febrero de $1977 .^{29}$

\footnotetext{
27 Entrevista a Carlos García Valdés, 18 febrero 2015.

28 El País, 11 octubre 1977.

29 El País, 12 febrero 1977.
} 
Otros acontecimientos les fueron reafirmando en la necesidad de contestar de forma violenta. Por ejemplo, la muerte de Agustín Rueda en la cárcel de Carabanchel en marzo de 1977, a la que respondieron con el atentado mortal a Jesús Haddad, Director General de Instituciones Penitenciarias. ${ }^{30}$ A consecuencia de esta serie de acciones, que tenían como objetivos a altos cargos del gobierno o militares, el Gobierno de la UCD se marcó la desaparición de GRAPO como el objetivo número uno. Esto afectó especialmente al PCE (r), que, si bien hasta entonces había sufrido la represión como otro grupo de ultraizquierda más, ahora se vio perjudicado en la confusión con los comandos armados.

En octubre de 1977 caía la plana mayor del PCE (r) en la reunión plenaria del Comité Central por la acción de un infiltrado de la Policía. Sin embargo, no pudieron acusarles de gran cosa, aunque algunos como Arenas fueron condenados por asociación ilícita y propaganda ilegal. Con su detención pasaron por la DGS donde denunciaron torturas. ${ }^{31} \mathrm{El}$ cerco al GRAPO se acrecentó con la llegada del militar Antonio Ibáñez Freire al Ministerio de Interior en 1979. Este contó con la ayuda del célebre comisario Roberto Conesa y de Antonio González, Billy el Niño, otro conocido policía del tardofranquismo y la Transición, al que acompañaba una oscura fama como torturador. ${ }^{32}$

Pese a estas caídas, GRAPO demostró una impresionante capacidad para recuperarse. El Gobierno creyó muchas veces que esta organización había quedado aniquilada y estos resurgieron, aunque cada vez con menos fuerza. Tras el repunte de atentados y víctimas mortales de 1979, su actividad como grupo se dejaría sentir más en las cárceles que fuera de ellas. Todo esto era patente en el sentir de los militantes, que iban perdiendo su confianza en la dirección y se quedaban un poco aislados con respecto a la realidad:

«Ahora lo veo. La organización se desmoronaba. Yo hacía más de un año que políticamente había perdido toda iniciativa. Los caminos de la realidad política y los de la organización hacia mucho que no se encontraban ningún punto común. Entonces ya se estaba de lleno inmerso en una dinámica que se haría más evidente con el tiempo. Éramos nada

\footnotetext{
${ }^{30}$ H. Roldan Barbero, op . cit., p. 75-78.

31 J. García Martín, op. cit., pp. 172-179. R. Gómez Parra, op. cit. p. 103

32 R. Gómez Parra, op. cit., p. 130.
} 
más que una mínima estructura, con unos intereses propios, enfrentados a unos cuerpos de seguridad del Estado. La sociedad quedaba al margen.» ${ }^{33}$

\subsection{Presos de GRAPO en Soria y Zamora (1978-1979)}

A resultas de las sucesivas detenciones, la historia del PCE (r) y GRAPO se empezaba a escribir tras los muros de la prisión. Tras cortas estancias en Carabanchel y Burgos ${ }^{34}$, los presos fueron agrupados en la cárcel de Soria, mientras que las mujeres eran recluidas en Yeserías. En Soria estuvo la mayoría del colectivo entre enero y diciembre de 1978, aunque algunos ya llevaban allí desde las detenciones por la «Operación Cromo». ${ }^{35}$

El comienzo de los traslados de miembro de ETA político militar a la prisión soriana, así como un intento de fuga de los presos de GRAPO fueron los motivos para su traslado a Zamora. ${ }^{36}$ Una vez allí, pensaron en una fuga desde el primer momento. La cárcel castellana estaba construida a base de piedras, arena y cal, que además estaban erosionadas, con lo cual la excavación parecía fácil. Además, descubrieron que justo debajo de la escalera de la terraza había una cámara de aire de dos metros y que las puertas del interior eran de fácil apertura o destrucción..$^{37}$

Lograr plena libertad de movimientos para excavar fue difícil debido al régimen al que estaban sometidos en Zamora. Por ello, se pusieron en huelga de hambre a los veinte días de su llegada. Dos de las primeras prerrogativas que consiguieron del director fueron la negativa a pasar los recuentos en formación y la concesión de materiales para instalar un taller de trabajos manuales, con lo que consiguieron los utensilios para poder excavar el túnel. Al conseguir estas mejoras abandonaron la huelga y comenzaron a trabajar. Ese túnel pasó inadvertido durante seis largos meses, incluso para la brigada de Roberto Conesa que visitó la cárcel en noviembre. ${ }^{38}$

\footnotetext{
${ }^{33}$ F. Novales, op. cit., p. 84.

34 F. Brotons Beneyto, op. cit., pp. 215-219.

35 Ibid., pp. 219-227.

36 R. Gómez Parra, op . cit. p. 210.

37 «Así fue la gran evasión de los GRAPO» en El País, 13 enero 1980.

38 Ibid.
} 
Los presos tuvieron un problema añadido a partir de octubre con la llegada de un nuevo director, Pedro Romero Macías, procedente de Basauri. Este estaba acostumbrado a lidiar con los presos de ETA y se sorprendió de los privilegios que tenían en la cárcel castellana. Ante el intento de imponer el régimen anterior a las mejoras, los presos de GRAPO desarrollaron una nueva huelga de hambre que paralizó un mes la construcción del túnel. Sin embargo, ante la proximidad de la fecha elegida para la fuga abandonaron la huelga para seguir con el plan previsto. ${ }^{39}$

Dentro de la prisión, los internos de GRAPO se organizaban en forma de comuna. Esta tuvo que decidir cuantos presos podrían fugarse sin levantar sospechas. Se resolvió que se marcharían cinco de sus líderes: Abelardo Collazo, Enrique Cerdán, Francisco Brotons, Juan Martín Luna y Fernando Hierro Chomón. El día elegido era la noche del 18 de diciembre de 1979. El resto debían disimular su ausencia en uno de los recuentos, que se realizaba en la sala común, por lo que los fugados tendrían así cuatro horas de margen desde las siete y media de la tarde hasta las once y media. ${ }^{40}$ Fue en ese momento cuando los funcionarios se dieron cuenta, pero cuando la dirección se puso en contacto con el Ministerio de Justicia era demasiado tarde. ${ }^{41}$

Los presos no quisieron contar con ayuda exterior en la fuga, por miedo a posibles delaciones, por lo que tuvieron que marchar por sus propios medios a sus destinos. Brotons y Collazo caminaron en dirección a Galicia, mientras que Hierro y Cerdán fueron a Burgos. Cuenta Gómez Parra, que Martín Luna se quedó enganchado en el túnel, por lo que salió el último cuando ya no había rastro de sus compañeros. Vagó durante días e incluso estuvo a punto de morir congelado, hasta llegar a León donde pasó unos días durmiendo en unas obras. ${ }^{42}$ Los que peor lo pasaron fueron, no obstante, los que se quedaron en Zamora, atosigados por los funcionarios y que posteriormente serían trasladados a Puerto de Santa María y Herrera de la Mancha como castigo por la fuga de sus cinco compañeros.

«Nos despertaron a las cuatro de la madrugada. Sonó un silbato y las puertas se abrieron. Entraron cuatro diluvios en cada celda y leye-

\footnotetext{
39 «Así fue la gran evasión de los GRAPO» en El País, 13 enero 1980.

40 R. Gómez Parra, op. cit., p. 212.

41 «Así fue la gran evasión de los GRAPO» en El País, 13 enero 1980.

42 R. Gómez Parra, op. cit., pp.212-213.
} 
ron una lista. Al que estaba en ella le dieron quince segundos para que se vistiera, lo esposaron y se lo llevaron. A la mañana siguiente, por la ventana, hicimos recuento: faltaban veinte camaradas. Nos pusimos en huelga de hambre (...) Estuvimos en huelga diecinueve días. No llegaron telegramas. Los camaradas estaban en Herrera y el Puerto de Santa María. Nos recomendaban no continuar la huelga». ${ }^{43}$

\section{Vivir y morir en Herrera de la Mancha (diciembre 1979- noviembre 1983)}

\subsection{El traslado}

En la prensa de aquellos momentos se discutía acerca de la inseguridad de las cárceles españolas, pocos meses después de que hubiese sido aprobada la ley penitenciaria. Las críticas arreciaron en la prensa tras la fuga de los GRAPO de Zamora.

«Se nos han dado pruebas repetidas de la escasa seguridad que los establecimientos penitenciarios tienen en este momento. Las cárceles españolas son inseguras por partida doble: por un lado, y testimonio irrebatible de ello lo constituye la fuga de los cinco miembros del GRAPO de la cárcel de Zamora, no son establecimientos que permitan a la sociedad conciliar tranquilamente su sueño, porque los reclusos (ocurrió antes en Barcelona y en otros establecimientos) escapan con una facilidad absolutamente pasmosa». ${ }^{44}$

Por su parte, el Ministro de Justicia, Iñigo Cavero, insistía en la necesidad de tener una cárcel especial para terroristas. ${ }^{45}$ Estas y otras manifestaciones estaban gestando la utilización de Herrera de la Mancha como prisión para miembros de organizaciones armadas, al estilo de otras centros europeos. Por ejemplo, la República Federal Alemana había internado en Stammheim a los presos de la Baader Meinhof, los del IRA se encontraban en Maze, así como los de Brigate Rosse eran destinados al penal sardo de Asinara. ${ }^{46}$

${ }^{43}$ F. Novales, op. cit., p. 136.

$44 A B C, 29$ diciembre 1979.

45 ABC, 19 diciembre 1979.

46 S. Aust, Baader Meinhof: The inside history of the RAF. Oxford University Press, 2009. M. Sanna, «Il carcere dell'Asinara. Gli anni del supercarcere» en Diacronie. Studi di Storia Contemporánea, n. ${ }^{\circ}$ 2, 1, 2010. 
Enrique Galavís, Director General de Instituciones Penitenciarias tras la marcha de Carlos García Valdés, tomó buena nota de esa corriente de pensamiento. El día 26 de diciembre, solo ocho días después de la fuga, eran trasladados 22 presos de GRAPO desde Zamora. 13 de ellos irían a Herrera y 9 a Puerto de Santa María ${ }^{47}$ Era la confirmación de la frase que se le atribuye de que «a los grapos habrá que meterles en cajones de cemento». ${ }^{48}$

Parece obvio que el traslado suponía un castigo por la fuga de Zamora. Sin embargo, no es descabellado pensar que posiblemente hubiesen sido trasladados con el tiempo a Herrera de la Mancha con el fin de estrechar el cerco a la organización armada. De hecho, una reacción tan rápida nos puede indicar que esa posibilidad ya era contemplada. La fuga, por tanto, podría haber acelerado los planes del Gobierno de convertir a Herrera en cárcel para presos de organizaciones armadas.

El director de Herrera de la Mancha por aquel entonces, Santiago Martínez Motos, justificaba el traslado basándose en el artículo 10.3 de la Ley Penitenciaria, referente a la limitación de actividades en común y el mayor control de los reclusos. En principio se aducía que su traslado a Herrera sería temporal, hasta que desapareciesen las razones que motivaron su actitud en la prisión de origen, algo un tanto contradictorio porque venía motivado por una fuga. Igual que en el caso del traslado de los presos sociales en 1979, la mayoría de ellos los más combativos en sus prisiones de origen, Herrera volvía a funcionar como cárcel de castigo para «corregir» el comportamiento de los presos. ${ }^{49}$ Asimismo, iban a parar a la cárcel más moderna del Estado, justo después de que se hubiese destapado la realidad sobre sus métodos, tras la denuncia colectiva que llevó al banquillo de acusados a doce funcionarios de esta prisión por malos tratos.

La prisión de máxima seguridad de Herrera de la Mancha había sido inaugurada en julio de 1979, situada en la localidad ciudadrealeña de Manzanares, a pocos kilómetros del núcleo urbano, en la carretera que une dicha población con Argamasilla de Alba. Se realizó una enorme inversión para la época, 600 millones de pesetas, contaba con los más modernos sistemas de seguridad y una capacidad para 240 re-

\footnotetext{
47 Diario 16, 27 diciembre 1979.

48 AFAPP, Op. cit, p. 38.

49 El País, 27 diciembre 1979.
} 
clusos ${ }^{50}$ Inicialmente fue concebida como una cárcel de cumplimiento de ámbito provincial, dentro de la política del gobierno de Adolfo Suárez de adaptar la infraestructura penitenciaria a los nuevos tiempos. ${ }^{51} \mathrm{Sin}$ embargo, las necesidades de la reforma penitenciaria llevaron a Herrera a convertirse en una cárcel de máxima seguridad donde mandar a los presos conflictivos de otras cárceles. Como señalaba García Valdés: «La reforma penitenciaria que estamos realizando no debe identificarse con este nuevo centro, sino que va destinada a esos reclusos que representan entre el $80 \mathrm{y}$ el 90 por ciento, que merecen todo tipo de ayuda para su reinserción en la sociedad española». ${ }^{52}$

Los presos trasladados a Herrera eran la plana mayor del PCE (r) y de GRAPO. En cuanto al partido, se encontraban Manuel Pérez Martínez, Comandante Arenas, Secretario general del PCE (r) y Juan José Crespo Galende, responsable de propaganda. También llegaban tres de los inculpados por el atentado de Haddad: Juan José Muiños Formoso, Francisco Echeverría Pardo y Andrés Mencia Bartolomé. Por otro lado, estaban Manuel Gil Araujo, implicado en el secuestro de Oriol y Villaescusa y Joaquín Vieites, presunto autor del asesinato de un policía en el metro de Barcelona. El resto estaban acusados de atracos y lanzamiento de cócteles molotov: Juan José Díaz Fernández, Ángel Collazo Araujo, Manuel Casinelle Rodríguez, Joaquín Calero Arcones, Adolfo Caballero Carbonell y Luis Bermejo Villegas. ${ }^{53}$ Mientras tanto, a la prisión gaditana de Puerto de Santa María eran trasladados, entre otros, José María Sánchez Casas, al que se consideraba responsable de los comando de los GRAPO y José Balmón Castell, responsable de organización del PCE(r).$^{54}$ Los presos interpretaron el traslado a Herrera como la llegada a una «cárcel de muerte»:

«Desde un lugar de la Mancha, así comenzó Cervantes su Quijote estando preso en la cárcel de Sevilla. Y precisamente ese «lugar de la Mancha» fue el escogido por el gobierno español para instaurar su cárcel de la muerte, copiando un modelo ya diseñado y experimentado por

\footnotetext{
50 DGIP, Informe general sobre el año 1979, DGIP, Madrid, 1980.

51 El País, 14 noviembre 1976.

52 Lanza. 15 julio 1978.

53 Diario 16, 27 diciembre 1979.

54 Diario 16, 27 diciembre 1979.
} 
el gobierno socialdemócrata alemán que llevó al suicidio a los principales dirigentes de la Fracción del Ejército Rojo Alemán». ${ }^{55}$

Como consecuencia de este traslado, el ayuntamiento de la ciudad de Manzanares, a 10 kilómetros de Herrera de la Mancha, reiteró la solicitud al Ministerio del Interior para que se crease una comisaría de Policía Nacional en la localidad, ante la inquietud que causaba en esta zona la presencia de este tipo de presos, considerados como peligrosos, aunque esa petición no llegó a concretarse. ${ }^{56}$

\subsection{El inicio de la resistencia}

Hemos entendido el paso de los presos de este colectivo por Herrera de la Mancha en clave de resistencia y de lucha, en consonancia con lo que para ellos significó la estancia en este centro. Por un lado, resistencia contra el sistema penitenciario, que se veía encarnado en la prisión manchega en uno de sus peores ejemplos; por otro, lucha contra las condiciones de esta prisión y, por ende, de todo el sistema penitenciario, así como contra el estado en clave ideológica. Para ello, llevaron a cabo un repertorio de acciones clásicas de los colectivos de presos políticos como la huelga de hambre. Este tipo de presos tiene una mayor facilidad que los presos comunes para resistir la prisionización, es decir, la adopción de una cultura carcelaria, motivada por el encarcelamiento. El hecho de estar todos juntos en la misma prisión y mantener una ideología común, hace más llevadera la estancia entre rejas y le da un sentido a la misma. 57

Los incidentes en Herrera de la Mancha comenzaron nada más llegar de la conducción. Los presos denunciaron que los funcionarios los apalearon a su llegada y los llevaron directamente a aislamiento.

«La llegada a Herrera fue ya impresionante. Nada más bajar nos encontramos con los antidisturbios en traje de campaña con sus cascos y porras. Junto a ellos un montón de funcionarios. ¡Dejar (sic) las cosas

55 Colectivo de presos de PCE (r) y GRAPO, op. cit., p. 5.

56 Lanza, 27 diciembre 1979.

57 P. Oliver Olmo, «Prisionización y bioprotesta» en I. Mendiola (ed.), Rastros y rostros de la biopolítica, Anthropos, Barcelona, 2009, pp. 247-270. 
ahí! ¡Contra la pared con los dedos! ¡Las piernas abiertas! Después del cacheo pasas a la galería. Allí lo mismo. ¡Venga cerdos, en pelotas! ¡Las manos atrás! Y golpes y palos porque no sabes si desnudarte o poner las manos atrás y lo hacen así para desconcertarte. ¡Flexiones! ¡A ver que tienes en el culo! ¡Venga otra vez! Y risas y golpes. Luego te ponen un buzo y unas zapatillas y te mandan para una ducha fría. De allí a la celda. Te devuelven algo de ropa, el mínimo, y te leen la cartilla. «Mira aquí vas a estar tiempo así que si no haces lo que te digamos vas a salir loquísimo. Y si se te ocurre pegar a un funcionario o insultarle tú verás, pero es posible que te suicides. De todos modos, si lo que piensas es en suicidarte nos pides lo que quieras: cuchillos, tijeras, cerillas... a nosotros nos da igual. Estas en Herrera». ${ }^{58}$

El director de la prisión echaba la culpa a los presos asegurando que «en un principio los ataques fueron verbales, profiriendo insultos a los funcionarios y a miembros de los cuerpos de, seguridad, a quienes constantemente calificaban de mercenarios, fascistas y asesinos. Poco después se abalanzaron contra dos funcionarios, a quienes intentaron agredir». ${ }^{59}$

Ante esto, los presos respondieron poniéndose en huelga de hambre desde el 29 de diciembre, algo a lo que le siguieron sus compañeros y compañeras de Puerto de Santa María y Yeserías respectivamente, en total 88 miembros de PCE(r) y GRAPO. ${ }^{60}$ Esta acción fue uno de los motivos de la visita de Martínez Motos a Madrid, a la Dirección General de Instituciones Penitenciarias, a causa del ambiente tenso que se vivía en Herrera. Esto sucedía al mismo tiempo que se estaba recaudando el dinero para la que saliese adelante la querella por malos tratos a presos comunes. Sin embargo, la huelga no pasó a mayores, ya que tenemos noticia de que el 7 de enero ya se había abandonado. ${ }^{61}$

Los internos también protestaban por el duro régimen de Herrera de la Mancha, ya que estaban aislados en sus celdas unas 23 horas al día. Si echamos un vistazo a las actas de las juntas de régimen de la prisión en estos meses vemos como se les imponían constantemente días de aislamiento como castigo. Asimismo, tenían interceptada la correspondencia. ${ }^{62}$

58 ERE, n. ${ }^{\circ} 38,1980$.

59 Diario 16, El País, 27 diciembre 1979. El País, 27 abril 1980.

60 Diario 16, 3 enero 1979. El País, 4 enero 1980.

61 Lanza, 8 de enero 1980.

62 Archivo de la Audiencia Provincial de Ciudad Real (AAPCR), Rollo 246/79, tomo 2. ${ }^{\circ}$, Sumario 22-1979. Manzanares, pp. 45-52, Actas de junta de régimen 2-10-21 enero 1980. 
En ese momento había 16 presos de GRAPO, por lo que vemos que la presencia de este colectivo no era muy grande en un penal que tenía capacidad para 250 personas. Su número osciló entre los 15 y 40 , mientras que el número de presos comunes era mucho más elevado, hasta llegar a $150 .{ }^{63}$ De todos modos, era un número representativo respecto a la totalidad de presos de GRAPO que era de unos 100 en todo el estado. ${ }^{64}$

Herrera de la Mancha jugaba el papel de cárcel de castigo para los presos del GRAPO. De hecho, los propios internos denunciaban que enfrentarse con los funcionarios en otras cárceles acababa con el traslado a la cárcel manzanareña. ${ }^{65}$ Asimismo, puede ser interpretada como una represalia contra la propia organización, una de las medidas de la política antiterrorista del gobierno español para desgastar la cohesión interna del grupo armado y del PCE (r).

En verano de 1980 se produjo la visita de la Comisión Especial del Congreso a Herrera con motivo de la investigación del caso de malos tratos a presos sociales. Estaba formada por Leopoldo Torres, del PSOE, José Sabalete, UCD, Simón Sánchez Montero, PCE y Juan María Bandrés de Euskadiko Ezkerra. Estos visitaron a los presos de GRAPO, o más bien lo intentaron, puesto que los senadores fueron recibidos de forma fría, e incluso hubo algunos insultos hacia el comunista Simón Sánchez Montero, calificado como «traidor de la clase obrera» por los presos, ya que algunos lo conocían por su militancia en movimientos obreros. ${ }^{66}$

La situación en Herrera de la Mancha también afectaba a los abogados, como refleja el artículo publicado por Miguel Castells el 8 de agosto de 1980 en El País. El letrado vasco había viajado en esas fechas a Herrera para hablar con su defendido, Félix Novales.

«Herrera de la Mancha incluye un sistema de medidas represivas sobre la comunicación de los presos políticos, y en bastantes casos, también de los sociales, con el abogado. La condición de esta cárcel es de una dureza extrema. No se podrá alegar el día de mañana que no lo hemos denunciado. Lo que sigue constituye un botón de muestra. Juzguen por él las posibilidades de defensa que puede tener en su interior los derechos humanos, a merced del régimen cerrado y sus funcionarios. (...)

\footnotetext{
63 El País, 8 octubre 1981.

64 AFAPP, op. cit., p. 40-41.

65 Colectivo de presos de PCE (r) y GRAPO, op. cit., p. 85.

66 ABC, 19 julio 1980. Colectivo de presos de GRAPO y PCE (r), op. cit., p. 107.
} 
Ya en el locutorio, dos o tres funcionarios asisten a la comunicación. No sé, con perdón, si va de testigos o de espías o de qué. Sí sé que no pierden sílaba. Que sus ojos permanecen clavados de comienzo a fin, escrutando el menor gesto, sobre defensor y defendido». ${ }^{67}$

\subsection{La vida en una cárcel de máxima seguridad}

Podemos seguir el día a día de los presos de PCE (r) y GRAPO en Herrera gracias al libro Crónicas de Herrera de la Mancha, que ya hemos citado anteriormente, elaborado por los propios presos y que constituye una gran guía acerca de la trayectoria del colectivo en esta prisión. En él se mezclan los sucesos cotidianos en el penal manchego, con otros pasajes más literarios.

Los presos estuvieron al principio aislados en celdas de castigo, como ya hemos comentado, en virtud del artículo 10 de la Ley General Penitenciaria. Solo podían salir al patio una hora cada día y lo hacían en solitario. Cuando pudieron estar en contacto, tras las huelgas que después contaremos, organizaron su vida en Herrera de acuerdo a su ideal de comuna. Se socializaban todos los alimentos y utensilios, así como se repartían labores como las de limpieza o de trabajos manuales. De igual modo, cuenta Francisco Brotons, que fueron construyendo su propia biblioteca y que organizaban asambleas en las que debatían sobre temas políticos. ${ }^{68}$ En ese tiempo incluso escribieron el libro Problemas filosóficos de las ciencias modernas $^{69}$, donde abordan cuestiones tan variopintas como una crítica al revisionismo marxista de Mario Bunge o una revisión de la teoría de la relatividad.

El régimen de la cárcel era muy estricto. Por ejemplo, cuando abrían la puerta de la celda, los presos tenían que permanecer en el fondo con las manos extendidas. Y si se abría el cangrejo, una especie de doble puerta, tenían que ponerse de espaldas con las manos atrás. En los recuentos también tenían que estar en el fondo de pie y mirando hacia la puerta, a la hora de comer recibían los platos en el suelo estando ellos en el fondo otra vez y tras ella no podían tener ni una cuchara ni un tenedor en la celda, así

\footnotetext{
${ }^{67}$ M. Castells, «Indefensión en Herrera de la Mancha» El País, 8 de agosto 1980.

68 F. Brotons Beneyto, op. cit., pp. 278-279.

69 J. M. Hernández, Problemas filosóficos de las ciencias modernas. Ediciones Contracanto, Madrid, 1989.
} 
como el colchón tenían que meterlo en el armario durante el día. No podían hablar con nadie, ni siquiera cantar. Si no se cumplía las normas, «venían con las porras». ${ }^{70}$

«Os voy a contar una anécdota para que veáis hasta qué punto. Llega un momento que en toda esa cárcel había 20 presos o por ahí, del PCE (r) y de los GRAPO. Tanto es así que había en los cuatro módulos, 2 personas, y en este caso había un compañero en todo un módulo previsto para 80 o así. Se podían permitir el lujo de tener todo un carcelón allí en el quinto carajo, picoletos, funcionarios, para guardar a 10 tíos. Uno en este módulo para 90 . Solo absolutamente, no podía hablar con nadie. Entonces en la hora de patio baja al patio más solo que la una, y va mirando y se encuentra que hay un hormiguero, las hormigas habían salido por el cemento. Entonces se bajaba las miguitas de pan, se las echaba a las hormigas y se quedaba ahí una hora de patio que tenía, mirando las hormigas en la soledad más absoluta. Y allí tenían las cámaras observando, «que mira ese hijo de puta». Al día siguiente, achicharraron el hormiguero. Esa la concepción de las cárceles de la democracia, sobre todo para la represión político. El aislamiento y a tomar por culo. Restricciones». ${ }^{71}$

A los presos se les interceptaba la correspondencia, de hecho, denunciaban que el $90 \%$ de las cartas que mandaban no llegaban a su destino. Igualmente, las comunicaciones con sus familias y sus abogados también eran intervenidas. La prensa también era censurada, hasta el punto de no incluir las noticias de las huelgas laborales. Solo podían leer periódicos de ideología conservadora como Ya y Pueblo y les cacheaban una vez por semana y siempre que salían. ${ }^{72}$ De igual forma, los presos denuncian en sus escritos que las palizas eran parte del día a día, así como denunciaban abusos en las conducciones a los juicios. ${ }^{73}$ No solo a ellos, dado que los funcionarios no habían dejado tranquilos a los sociales tras la denuncia

${ }^{70}$ Colectivo de presos de PCE (r) y GRAPO, op. cit., pp. 18-19.

71 Entrevista a José Balmón, 25 enero 2015.

72 «Represión en las cárceles» en Punto y Hora de Euskal Herria, n. ${ }^{\circ}$ 168, marzo 1980. «Desde Herrera de la Mancha. GRAPO» en Punto y Hora de Euskal Herria, n. ${ }^{\circ} 180$, junio 1980.

${ }^{73}$ Colectivo de presos de PCE (r) y GRAPO: Op. cit., p. 25. F. Novales, op. cit., p. 161 . 
«Un día metieron a otro preso en mi galería. Entonces empecé a intuir el objeto de aquel infierno. Le habían puesto un par de celdas más allá de la mía; pero el pasillo agigantaba los sonidos y casi podía enterarme de cada susurro. Al poco, llegó Barroso. «Ya he visto que no nos andamos con tonterías. Aquí tienes papel y lápiz. Te voy a dar una semana para que te lo pienses y lo cuentes todo. Y si no..., empezamos otra vez» ¡No podía ser posible! ¡Sí, lo era! ¡Eso era fundamentalmente Herrera!». ${ }^{.4}$

\subsection{Una huelga de hambre a muerte}

La situación de los presos de GRAPO en Herrera a comienzos de 1981 no había mejorado, ya que el régimen interno seguía siendo igual de duro. Llevaban un año en aislamiento casi total, con apenas dos horas de patio al día, restricciones en sus comunicaciones y denunciando que las palizas continuaban. ${ }^{75}$ Por todo ello, comenzaron a principios de año una huelga de hambre que desarrollarían de forma cíclica. Los primeros en iniciar la acción fueron Joaquín Vieites Santos y Pablo Fernández Villabeitia el 14 de febrero de 1981 y pronto se les unirían otros presos en Zamora, Puerto de Santa María y Yeserías. Consiguieron algunas mejoras, como más horas de patio o comunicaciones sin censura pero no durarían en el tiempo, por lo que pronto reanudaron la huelga ${ }^{76}$

La huelga de hambre constituye una de las pocas armas de las que dispone el preso para poner en jaque a la administración. Esta acción requiere un alto grado de compromiso y de resistencia, no solo física, sino también mental. Constituye una prueba del repertorio de protestas que el preso lleva a cabo con su propio cuerpo como instrumento, bioprotesta, y de una forma pacífica. Esta huelga de hambre, así como otro tipo de protestas que llevaron a cabo durante su estancia en Herrera de la Mancha es lo que venimos entendiendo como resistencia al régimen de la prisión manchega y, en definitiva, a la prisionización. ${ }^{77}$

Hay que tener también en cuenta que esta huelga de hambre se desarrolló de forma paralela a la llevada a cabo por los presos de IRA en Gran

\footnotetext{
${ }^{74}$ F. Novales, op. cit., p. 151.

75 Egin, 28 mayo 1981.

76 AFAPP, op. cit., p. 19.

77 Oliver Olmo, P. Op. cit.
} 
Bretaña. Esta se desarrolló por similares causas, en especial por mejorar sus condiciones en las cárceles inglesas y obtener el estatuto de presos políticos. En esas huelgas de hambre a muerte murió, entre otros, Bobby Sands, quien había sido elegido miembro del Parlamento Inglés y que falleció el 5 de mayo de 1981 en la prisión norirlandesa de Maze, tras 66 días en huelga de hambre.

Los presos de Herrera protestaban por el régimen de las cárceles en las que estaban sometidos y por el trato «humillante y vejatorio a que son sometidos los presos en la citada prisión especial». ${ }^{78}$ Declaraban que solo dejarían la huelga de hambre si se daban garantías sobre su salida de la cárcel manchega y su reagrupamiento en otra prisión. Asimismo, ponían a la Tercera Galería de la cárcel de Carabanchel, con un régimen menos duro y en el que se les permitía organizarse a modo de comuna, como el ejemplo de la situación que ansiaban en la cárcel en la que fuesen reagrupados. ${ }^{79}$

En mayo, cuatro internos tuvieron que ser trasladados al Hospital Penitenciario ante su deterioro físico por lo prolongado de su ayuno, entre ellos Pablo Fernández Villabeitia que llevaba un mes continuado de huelga, y Juan José Crespo Galende que llevaba dos meses sin comer, aunque en ese momento no se temía por la vida de ambos. ${ }^{80}$

En otro sentido, la huelga podía ser interpretada como una lucha de los presos políticos contra la reforma penitenciaria en sí. Si la reivindicación triunfaba, sería un duro golpe para el «modelo Herrera» en particular, y en la reforma penitenciaria en general, que tenía a esta cárcel como un referente. Era la única forma en que los presos podían luchar por unos acuerdos mínimos que ellos consideraban necesarios para que pudiesen aguantar en prisión, como señalaba el abogado de presos de GRAPO José Manuel Olarieta. «Herrera no es la guerra particular de unos pocos, sino la de todo aquel que luche contra la «reforma» (en concreto la penitenciaria como parte de aquella) por una verdadera ruptura con el estado actual de cosas». ${ }^{81}$

Los presos denunciarían presiones por parte de la Dirección General de Instituciones Penitenciarias y de la dirección de Herrera de la Mancha

\footnotetext{
78 Egin, 23 mayo 1981.

79 AFAPP, op.cit., p. 55.

80 Diario 16, 2 mayo 1981. El País, 16 mayo 1981.

${ }^{81}$ Punto y Hora de Euskal Herria, n. ${ }^{\circ}$ 230, junio 1981.
} 
para que dejasen la huelga de hambre. Incluso algunos de ellos aseguraron que les acercaban la comida para intentar que depusiesen su actitud. ${ }^{82}$

\section{5. Кера}

La situación de los presos que permanecían en huelga de hambre empezó a ser crítica a finales de mayo, en especial la de Juan José Crespo Galende, quien había sobrepasado los 70 días de huelga de hambre desde que comenzase el ayuno el 14 de marzo de 1981. Se encontraba en estado crítico en el Hospital Penitenciario, donde había sido trasladado. ${ }^{83}$

El entorno de los presos culpaba de la situación al Ministerio de Justicia y la Dirección General de Instituciones Penitenciarias, ya que habían permanecido ajenos a este problema, sin intención de remediarlo ni de acceder a algunas demandas de los internos ${ }^{84}$ En este sentido, es cierto que la administración penitenciaria permaneció tibia en sus intentos de negociación. Siempre se mantuvo reacia a trasladar a los reclusos de GRAPO de Herrera de la Mancha, algo que era una de sus principales reivindicaciones.

Ante esta actitud, Crespo Galende dio un paso más y tomó la decisión de hacer huelga de sed como paso final. ${ }^{85}$ La situación se convirtió en un pulso entre el GRAPO y el Gobierno no ya solo sobre la situación concreta de estos presos en la cárcel, sino acerca de todo el entramado penitenciario español. El gobierno temía, lógicamente, las consecuencias que pudiesen conllevar la muerte de un preso, por lo que podría significar, como sintetizaba José Manuel Olarieta.

«Mira, si un preso en huelga de hambre muere es un suicidio, pero, claro, como todo esto es un proceso, todo depende de si la Dirección de Prisiones tiene intención de acceder a la reivindicaciones o no, entonces solo le quedan dos caminos para evitar la muerte; o bien forzar a una persona a comer, lo que es ilegal porque no hay ninguna disposición que obligue a una persona a comer, o bien acceder a las peticiones

\footnotetext{
82 AFAPP, op. cit., pp. 45-52

83 El País, 28 mayo 1981.

${ }^{84}$ Egin, 22 mayo 1981.

85 Egin, 6 junio 1981.
} 
(...) Tampoco se podría hablar de suicidio, si Crespo accede a volver a Herrera (a recoger colillas como él dice) ya que esa prisión extermina al preso». ${ }^{86}$

Se denunció que Crespo Galende había sido forzado a alimentarse. Fernández Villabeitia, que estuvo cerca de él en su calvario, lo señaló en su momento, apuntando a que fueron órdenes directas del Ministro de Interior Juan José Rosón. ${ }^{87}$ Todo esto supuso una tortura añadida en los últimos días de Crespo, pues se le mantuvo con vida de forma artificial. Pese a ello, los miembros de la AFAPP calificarían de ejemplar la actitud de los sanitarios que atendieron a Kepa, ya que se negaron a aplicar los dictámenes de las autoridades en cuanto a la alimentación forzosa de los huelguistas. ${ }^{88}$

El tema de la alimentación forzada volvió a la palestra en la huelga de hambre de los presos de GRAPO entre 1989 y 1990, e incluso acabó generando un enfrentamiento entre gobierno, jueces y médicos en torno a ese tema. Se generó un bucle por el cual se alimentaba a los presos cuando estaban inconscientes, alargando de este modo la agonía, en una tortura sin fin. La organización maoísta respondió asesinando a uno de los médicos que había autorizado alimentar forzosamente a uno de los presos, José Ramón Muñoz Fernández, el 27 de marzo de 1990 en Zaragoza. ${ }^{89}$

Cuenta Fernández Villabeitia que él pidió a Crespo ponerse en huelga de sed, porque él era soltero y «estaba deseando acabar aquello como fuera». Sin embargo, Crespo «se negó en redondo, dijo que no se me ocurriera hacer nada por mi cuenta y que si llegase el momento en que tuviéramos que ponernos en huelga de sed, como ocurrió, él sería el primero y que me dejara de decir tonterías (...) Para Kepa lo importante era ganar, su propio estado le traía sin cuidado». ${ }^{90}$

Crespo Galende fue trasladado desde el Hospital Penitenciario a la Unidad de Vigilancia Intensiva Hospital de la Paz el día 8 de junio de 1981 en estado comatoso. Ocho días más tarde Pablo Fernández Villabeitia era llevado también al hospital madrileño ante su deteriorado estado

\footnotetext{
${ }^{86}$ Punto y Hora de Euskal Herria, n. $^{\circ} 230$, junio 1981.

${ }^{87}$ Egin, 9 junio 1981. Colectivo de presos de PCE (r) y GRAPO, op. cit., pp. 199-209.

88 AFAPP, op.cit., p. 27.

89 El País, 28 marzo 1990.

90 Colectivo de presos de PCE (r) y GRAPO, Op. cit, pp. 195-198.
} 
de salud. ${ }^{91}$ El día 19 de junio la vida se escapaba del cuerpo de Juan José Crespo Galende tras 86 días sin ingerir alimento sólido. El diagnóstico de la muerte era «una sepsis de origen pulmonar con síndrome de dipstres respiratorio y coagulación intravascular diseminada, que origina una insuficiencia respiratoria y hemorragia generalizada». En el momento de su muerte ya había perdido la visión. ${ }^{92}$

Kepa, como era conocido por sus compañeros, había sido responsable del PCE (r) en la zona industrial de Bilbao. Estaba en la cárcel desde 1979, tras haber sido detenido en septiembre por asociación ilegal como miembro del aparato de propaganda del partido. El día 18 de ese mismo mes había ingresado en la cárcel de Carabanchel y había sido condenado a 37 años de cárcel de los cuales solo había cumplido dos entre la prisión madrileña, Zamora y Herrera de la Mancha. ${ }^{93}$ Recordaba Félix Novales que Crespo había reconocido ante los miembros de la comuna que nunca había tenido valor para matar. Lo que en un grupo de este estilo normalmente era signo de cobardía, a él le hacía diferente. ${ }^{94}$

Enrique Galavís, director general de Instituciones Penitenciarias se disculpaba diciendo que «hemos hecho lo humanamente posible por salvarle la vida. En La Paz se han volcado con él, y yo personalmente he estado diariamente en contacto con este centro para conocer su estado de salud». ${ }^{95}$ Asimismo, se hablaba de la oferta que había transmitido la Dirección General a los presos, que habían consistido en reducir el tiempo en las celdas y poder disfrutar de más tiempo en el patio.

El gremio de los abogados se movilizó ante esta muerte. González Berzosa, por su parte, apostaba por «meter mano al sistema penitenciario y acabar con la tortura de Herrera de la Mancha». ${ }^{96} \mathrm{El}$ grupo de abogados jóvenes de Madrid, muy implicados en el caso Herrera, resaltaban los efectos psíquicos que producía una prisión como esta:

«...estas prisiones suponen la destrucción del individuo y ninguna persona, sea delincuente común o político de cualquier organización, debe ser internada en centro semejante. Numerosos compañeros de este

\footnotetext{
91 El País, 9-16 junio 1981.

92 El País, 20 junio 1981.

93 El País, Diario 16, ABC, 20 junio 1981.

94 F. Novales, op. cit., p. 175.

95 El País, 20 junio 1981.

${ }_{96}$ Egin, 20 junio 1981.
} 
grupo y del resto del Estado han venido denunciando constantemente, incluso desde antes de que se intentase justificar la existencia de esta aberrante prisión con el envío de presuntos «terroristas», esta flagrante violación de los derechos humanos que, en definitiva, equivale a una pena de muerte lenta, ya física, ya psíquica. El miembro de los GRAPO Crespo Galende ha sido la primera víctima física mortal». ${ }^{97}$

En este sentido, no se pueden obviar las responsabilidades que los estamentos gubernamentales y penitenciarios tuvieron en el fatal desenlace de Juan José Crespo. Un interno siempre es responsabilidad de la administración, sobre todo si este se encuentra en huelga de hambre. Por mucho que este sea tildado de terrorista, eso no es excusa para que se haga dejación de funciones. De igual forma, debemos valorar la influencia de expresiones como «cajones de cemento», como lo más idóneo para encarcelar a presos de GRAPO u organizaciones similares. Lo que se dice sobre el carácter de la cárcel repercute en el uso que posteriormente se da a la misma. Por último, esta huelga también había sido motivada por las promesas incumplidas de la administración penitenciaria, que no había mantenido los acuerdos con los que había terminado la primera parte de esta acción.

Por otro lado, también habría que cuestionarse acerca de las responsabilidades que tuvieron la dirección del partido y de GRAPO, que permanecieron inflexibles en sus peticiones mientras uno de sus miembros agonizaba en la cama es un hospital. Por mucho que estuviesen protestando contra un régimen carcelario abusivo y que Crespo Galende hubiese aceptado en cierto modo su destino, dispuesto a marcharse del mundo luchando (contra unas condiciones que podrían ser consideradas como infrahumanas), no se puede dejar morir a un miembro de una colectividad. Los mártires nunca pueden entenderse como una victoria, son una derrota por cuanto el material humano es totalmente irremplazable. De hecho, esta muerte no cambió radicalmente el régimen de Herrera, si es cierto que influyó, pero sus compañeros y los presos que vinieron después tuvieron que seguir luchando. Asimismo, nos resistimos a pensar que Kepa hubiese abandonado la idea de vivir con su compañera y su hijo y su mayor deseo sería salir de la cárcel para poder vivir con ellos. En definitiva, se pagó un alto precio en esta huelga, que fue uno de las muchas circunstan-

97 Grupo de abogados jóvenes, «La muerte de los GRAPOS» en El País, 1 julio 1981. 
cias que motivaron la ruptura dentro del grupo y que acabaron con la salida del mismo de históricos como Félix Novales.

Tras la muerte de Crespo hubo algunos incidentes entre manifestantes y Policía en País Vasco, de donde era natural. ${ }^{98}$ Su entierro tuvo lugar el 27 de junio, con la bandera de la República Popular sobre su féretro, mientras que las banderas de Euskadi y del PCE (r) presidían la ceremonia junto a una pancarta que rezaba, «Crespo, muerto por la libertad de su pueblo». Hubo muestras de solidaridad en País Vasco, así como en algunas plazas fuertes del PCE (r) como Vigo o Cádiz, y gestos de apoyo en las marchas anti-OTAN y actos organizados por la AFAPP. ${ }^{99}$

Especialmente emotiva era la carta de despedida de su compañera María Asunción Alonso, Asun como la conocían todos, a la que dejaba con una niña pequeña, Itziar. «Juanjo estaba plenamente seguro de alcanzar la victoria en esta lucha y sus últimas palabras, sus últimos pensamientos fueron dedicados a todos los camaradas y a todos los luchadores». ${ }^{100}$ En una entrevista posterior, Asun destacaba la normalidad de su vida con Kepa, aun viviendo en la clandestinidad.

«Él era un hombre entrañable, eso que se conoce como una persona buena. Vivíamos en la más estricta clandestinidad. Así que nos unían más cosas que a una pareja normal, pues nuestra vida tampoco era normal. Eso hacía que en los raros momentos de descanso de que gozábamos experimentáramos una felicidad extraordinaria. Él era serio, pero alegre con los amigos y los camaradas. Si en alguna rara ocasión tenía ocasión de tomar unos vinos con la gente del barrio que le conocía y quería, venía rebosante feliz. Para él nuestra hija y yo éramos aparte del partido toda su vida. Fueron unos años en los que, por encima de los sinsabores de la vida de la persecución, fuimos felices»..$^{101}$

Por último, también son muy sentidos los escritos que muchos de sus compañeros le dedicaron en el libro Morir para sobrevivir, en el que se repasan y denuncian los últimos momentos con vida de Juan José Crespo. Algunos de ellos aprovecharon para dar rienda suelta a su vena literaria, como Manuel Pérez Martínez, Arenas, quien le dedicaba un poema a Juan

\footnotetext{
98 Egin, 21 junio 1981.

99 AFAPP, op . cit., pp. 25-26.

100 Egin, 9 julio 1981.

101 Egin, 30 mayo 1982.
} 
José Crespo, que comenzaba de la siguiente forma: «A ti, Juan José, no te han quitado la vida. En tu sien no han clavado el filo de una pistola. A ti no te han asesinado. Tú te has dejado morir, para mostrar al mundo la llaga de la tortura, con tu cuerpo inmolado.»102

\subsection{La lucha continua}

Otros presos del PCE (r) y GRAPO, hasta diecisiete en diferentes cárceles españolas, siguieron con la huelga de hambre buscando mejoras tangibles. En Herrera de la Mancha continuaba con su reivindicación Andrés Mencia desde el 7 de junio. ${ }^{103}$ Esta acción acabó a finales de julio, al aceptar Instituciones Penitenciarias alguna de las condiciones de los presos, gracias a la mediación de Cruz Roja. ${ }^{104}$ El Gobierno no podía permitirse otra muerte así que admitieron que negociarían, y que trasladarían a los presos de Herrera en un plazo no superior a seis meses, algo que no cumplieron.

A causa de ello, en septiembre reanudaron la huelga de hambre. Los precursores fueron Francisco Brotons, José Balmón, Juan Jesús Muñoz Formoso, Manuel Parodi y Alfonso Rodríguez. Pronto, 19 de los 20 presos de PCE (r) y GRAPO que había en Herrera secundaron la huelga a causa de las deficiencias en el régimen carcelario, pese a las mejoras prometidas. Según los familiares, «los huelguistas ya no piden nada en concreto, sino que tratan de protestar contra todo un sistema que les impide mantener un régimen de vida normal y digno, y que pretende anularles física y moralmente», aunque también protestaban para impedir más traslados de compañeros a Herrera. ${ }^{105}$

Esta huelga tuvo una menor incidencia, probablemente porque nadie quería seguir el final trágico de Crespo. En Carabanchel nadie quería ser voluntario y al final fueron dos «líderes» como Hierro y Brotons los que se pusieran al frente, incluso Arenas en Herrera, pero la dejaron pronto. Novales criticó la mezquindad de los líderes del GRAPO y el partido, que manejaron a los presos en ocasiones como meros instrumentos, sin impor-

\footnotetext{
102 M. Pérez Martínez, «Juan José Crespo Galende», en AFAPP, op. cit., p. 123.

103 El País, 7 julio 1981.

104 Egin, 25 julio 1981.

105 El País, Lanza, 8 octubre 1981.
} 
tarles su estado físico o su propia vida mientras ellos dejaban la huelga a la primera oportunidad. ${ }^{106}$

Tras dos ayunos colectivos, los presos del GRAPO en Herrera dieron un giro en sus protestas y se declararon en huelga de desobediencia. Se negaban a seguir las órdenes de los funcionarios, así como a recibir visitas, cartas y cualquier otra comunicación con el exterior, salvo de sus abogados, con el fin de que no les pudiesen chantajear con ello. Esta actitud estaba motivado por el incumplimiento del acuerdo firmado con Instituciones Penitenciarias y Cruz Roja y por la situación precaria que seguían viviendo. ${ }^{107}$ No era la primera vez que utilizaban este repertorio, pues ya lo habían practicado a su llegada desde Zamora. ${ }^{108}$ Esta actitud motivó sanciones colectivas a los treinta presos herrerianos y, por tanto, más aislamiento. ${ }^{109}$

A la huelga de obediencia se sumó una nueva huelga de hambre, que no desembocó esta vez en una acción a muerte, con el fin de forzar el traslado desde Herrera a otra prisión en la que reagruparse con sus compañeros. ${ }^{110}$ Gracias a estas acciones, los presos consiguieron algunas pequeñas mejoras, sobre todo en cuanto al trato de los funcionarios en el día a día: «a base de protestas y enfrentamientos cotidianos que aquellos humillantes cacheos no pasaran del puro formalismo, les tocaban los tobillos y a veces un poco la cinturilla del pantalón, de ahí ya no pasaban». ${ }^{111}$

\subsection{Voto de (des) confianza al PSOE}

GRAPO anunció una tregua tras la victoria de Felipe González en las elecciones generales de octubre de 1982, con el fin de mostrar su disposición de negociar con el nuevo gobierno del PSOE, a quien, pese a la distancia ideológica, no consideraban totalmente un producto del franquismo como a la UCD. Sin embargo, los treinta y siete presos de PCE (r) y GRAPO en Herrera de la Mancha se negaron a entrevistarse con altos car-

106 F. Novales, op. cit., pp. 180-181.

107 El País, 20 marzo 1982. Egin, 1 abril 1982. Colectivo de presos de PCE (r) y GRAPO, op. cit., p. 35

108 F. Brotons Beneyto: Op. cit., p. 260.

109 Lanza, 11 abril 1982.

110 ABC, 17 abril 1982.

111 Colectivo de presos de PCE (r) y GRAPO, op. cit., p. 77 
gos del Ministerio de Justicia en enero de 1983, incluido Juan José Martínez Zato, el nuevo Director General de Instituciones Penitenciarias. ${ }^{12}$

Hubo conversaciones entre GRAPO y Gobierno a través de los internos de Herrera de la Mancha, con el fin de que la organización maoísta abandonase la lucha armada. Por su parte, estos pedían, ante todo, amnistía para sus presos. ${ }^{113}$ Las negociaciones fueron mantenidas por Manuel Pérez Martínez, Camarada Arenas, y José María Sánchez Casas por parte de los GRAPO, mientras que sus interlocutores fueron el subcomisario Ramón Lillo, jefe del Grupo del Grupo de Investigación y Vigilancia de la Audiencia Nacional, y un comandante de la Guardia Civil cuyo nombre no trascendió. El propio Arenas había manifestado al El País que «nosotros estamos por una negociación seria y exigimos, fundamentalmente, la excarcelación para los presos del PCE (r) y GRAPO en un plazo de aproximadamente dos años». Sin embargo, expresaba que los representantes del Ministerio de Interior les habían comunicado que no podían aceptar sus propuestas. ${ }^{114}$

En definitiva, esas conversaciones no pasaron de ser meros tanteos, en los que el Gobierno querría ver el estado de la organización, y en los que GRAPO se mantuvo rígido en sus condiciones. La muerte del militante Juan Martín Luna, abatido por la Policía en diciembre de 1982, en una actuación defendida por el ministro Barrionuevo, apartó la idea de que el PSOE no fuese a ser tan inflexible como sus predecesores en materia antiterrorista. $^{115}$

Los presos de GRAPO no abandonarían Herrera por estas conversaciones, ni por su continua presión contra el Gobierno. $\mathrm{O}$ al menos, no solo por eso. Pesaría mucho más la decisión del Ministerio de Interior de trasladar a los presos de ETA, a esta cárcel de máxima seguridad. En octubre de 1983, la prisión manchega se vació para posteriormente acoger a los presos de ETA. 108 presos abandonaban Herrera en ese mes, 37 de ellos de GRAPO y PCE (r). ${ }^{116}$

Estos serían concentrados de nuevo en Soria a partir de enero de 1984, previo paso por la prisión madrileña de Alcalá Meco. ${ }^{117}$ La estancia

\footnotetext{
112 El País, 17 de enero 1983.

113 Diario 16, 6 agosto 1983. F. Brotons Beneyto, op. cit., pp. 282-283.

114 El País, 13 agosto 1983.

115 El País, 22 enero 1985.

116 Egin, 25 octubre 1983.

117 El País, 6 de enero 1984.
} 
en la cárcel castellana se convertiría en una época de estudio, de hecho la llamarían la «Universidad de Soria», donde los presos del GRAPO y PCE (r) se dedicarían al estudio hasta la dispersión del gobierno socialista iniciada en 1989. Allí también surgieron problemas en el propio colectivo de presos, que acabaría con la defección de algunos militantes históricos como el propio Novales, o Andrés Mencia. ${ }^{118}$

Así acabó la historia de los presos de GRAPO en Herrera de la Mancha. Estos no olvidarían el tiempo que pasaron allí y se dirigirían en alguna ocasión hacia ella. Por ejemplo, en la huelga de hambre de los presos de ETA en marzo de 1985, a los que mostraron su solidaridad.

«Nosotros hemos pasado cuatro años en Herrera y nada de lo que allí sucede o pueda suceder nos va a sonar a nuevo. Echar por tierra los planes de aniquilación y conquistar las condiciones mínimas para llevar una vida digna en la cárcel, así como que nos sacasen de allí, nos costó duras luchas, numerosas y prolongadas huelgas de hambre y que nuestro camarada Juan José Crespo Galende, cayera muerto en el transcurso de una de estas huelgas parece ser que al Gobierno de los monopolios no le ha sido suficiente con este crimen. Y ahora vuelven a la carga con los militantes vascos encarcelados. Todos somos conscientes de que la única manera de hacer fracasar una vez más sus planes es con la lucha más consecuente, resistiendo. Hoy es en Herrera donde los presos políticos están sufriendo más duramente la venganza de los comunes carceleros, (...) Ni que decir tiene que los compañeros de ETA en huelga cuentan con todo nuestro apoyo y solidaridad». ${ }^{119}$

\section{Conclusiones}

A modos de conclusión, resolvemos que la historia de los presos del GRAPO en la prisión de Herrera de la Mancha comenzó en forma de castigo. La fuga en diciembre de 1979 de cinco dirigentes del PCE (r) y del GRAPO de la cárcel de Zamora provocó el traslado de sus compañeros a Puerto de Santa María y a Herrera de la Mancha. La prisión manchega fue utilizada en aquellos años como cárcel de castigo dentro del mapa penitenciario nacional. La modernidad y la tecnología de este nuevo penal estuvieron al servicio de ello.

118 R. Gómez Parra, op. cit., pp. 182-185. F. Novales, op. cit., p. 200.

119 El País, 28 marzo 1985. 
La prisión manchega estaba envuelta en aquellos momentos en un escándalo por los malos tratos y torturas que se habían llevado a cabo contra presos sociales y que acabaría con nueve funcionarios condenados. Por lo tanto, el traslado de los GRAPO a Herrera no podía ser únicamente una cuestión administrativa con la intención de dispersarlos en varias cárceles, sino que se les enviaba a la cárcel más dura de esos momentos, así como a Puerto de Santa María que también tenía fama de ser una de las peores prisiones del estado.

Estos presos serían los primeros de una organización armada que visitarían Herrera de la Mancha. GRAPO inauguraba así el historial de Herrera como parte de las medidas de las disposiciones antiterroristas de los siguientes gobiernos. Lo que hemos expuesto en este artículo es un buen ejemplo de como la política penitenciaria de estos años se plegaba completamente a los designios de la política de seguridad del gobierno. Esta experiencia sería aprovechada en el futuro, cuando los presos de ETA fueron trasladados a la prisión manchega a partir de noviembre de 1983.

La estancia de los presos de GRAPO y PCE (r) en Herrera de la Mancha se inscribe dentro de su lucha política. La cárcel ha sido una de las etapas vitales de estos militantes, donde se han dedicado a profundizar en su estudio político y tratar de poner en práctica sus ideales de comuna, una forma de resistencia a la experiencia carcelaria, porque lo que se pretende con la cárcel, en especial con este tipo de organizaciones, es desunir. En Herrera pusieron en práctica esta organización, socializando la comida y todas las pertenencias que tenían, así como dedicándose al estudio de forma conjunta, una vez que dejaron de estar sometidos al aislamiento casi total. De todos modos, también es cierto que dentro de estas organizaciones siempre existió una fuerte dependencia de los líderes en cuanto a la toma de decisiones.

En la prisión manchega utilizaron un repertorio de acciones bastante amplio, desde la huelga de hambre, hasta la de insubordinación a las órdenes de los funcionarios, con las que consiguieron algunas mejoras en el régimen de Herrera de la Mancha. Al igual que hemos comentado desde la perspectiva de las instituciones, también esta experiencia de los presos del GRAPO en Herrera fue posteriormente aprovechada por los presos de ETA, que repitieron parte de este catálogo de acciones. Estas formas de lucha se dirigieron a la pelea contra la violencia institucional que vivieron en el penal manchego, con un régimen carcelario sin parangón en el territorio nacional, con la más moderna tecnología al servicio del castigo. 
Juan José Crespo Galende es el nexo de unión permanente entre Herrera de la Mancha y GRAPO, un símbolo de la estancia de estos presos en el penal manchego y de su lucha en el mismo. Kepa murió tras más de ochenta días en huelga de hambre protestando por las condiciones de Herrera en particular y la de los presos de su colectivo en general. Una víctima que se cobró la prisión manchega, pero que también debe asumir todo el entramado carcelario de la reforma penitenciario, del cual Herrera era uno de sus símbolos. Una muerte que se podría haber evitado con un talante más dialogante por ambas partes, en especial por la Dirección General de Instituciones Penitenciarias.

La historia de GRAPO en Herrera terminó en noviembre de 1983. No fue tanto por las interminables protestas y luchas que llevaron a cabo para salir de aquella cárcel, sino por un cambio de tercio en la política antiterrorista. Mostrado el potencial de Herrera de la Mancha para albergar a presos de organizaciones armadas, se destinó en los años posteriores a los presos de ETA. 